\title{
Immunomodulatory effect of a formula developed from American ginseng and Chinese jujube extracts in mice*
}

\author{
Zhuo-ping YU, Dong-dong XU, Lai-feng LU, Xiao-dong ZHENG ${ }^{\dagger \ddagger}$, Wei CHEN ${ }^{\dagger *}$ \\ (College of Biosystems Engineering and Food Science, Fuli Institute of Food Science, Zhejiang Key Laboratory for Agro-Food Processing, \\ Zhejiang R\&D Center for Food Technology and Equipment, Zhejiang University, Hangzhou 310058, China) \\ †E-mail: xdzheng@zju.edu.cn; zjuchenwei@zju.edu.cn \\ Received July 13, 2015; Revision accepted Dec. 3, 2015; Crosschecked Dec. 16, 2015
}

\begin{abstract}
Background: American ginseng (Panax quinquefolius L.) and Chinese jujube (Zizyphus jujuba Mill.) are commonly used in traditional Chinese medicine to enhance immune function. Objective: The present study aimed to develop one Chinese prescription, Shenzao Cha (SZC), consisting of American ginseng and Chinese jujube, and systematically investigate its immunomodulation in healthy ICR mice. Methods: Normal ICR mice received intragastric administration of SZC $(1.3,2.6$, and $5.2 \mathrm{~g}$ raw material $/ \mathrm{kg}$ body weight) once daily for four weeks, while a control group received the same amount of sterile water. Results: SZC significantly increased the spleen and thymus indices and T-lymphocyte proliferation, while the T-lymphocyte proliferation in the $5.2 \mathrm{~g} / \mathrm{kg}$ group was 1.4 -fold higher than that in the control. Further, $1.3 \mathrm{~g} / \mathrm{kg} \mathrm{SZC}$ could markedly improve hemolytic activity by $25.2 \%$, and $2.6 \mathrm{~g} / \mathrm{kg} \mathrm{SZC}$ increased the NK cell activity by $78.6 \%$ relative to the control. In addition, the activities of antioxidant enzymes (superoxide dismutase, catalase, and glutathione peroxidase), that participated in modulating oxidative stress, were significantly increased in the liver, spleen, thymus, and serum, while the contents of malondialdehyde were dramatically decreased. Conclusions: SZC exhibited potent immunomodulatory effects on innate and adaptive immunity in healthy ICR mice, as well as potential antioxidant activity for prevention of oxidative stress, which was suggested to partly contribute to the immune enhancement.
\end{abstract}

Key words: American ginseng, Chinese jujube, Immunomodulation, Antioxidant activity http://dx.doi.org/10.1631/jzus.B1500170

CLC number: TS275.4

\section{Introduction}

The immune system and its response to specific stimulation are extremely complex and precisely coordinated to protect the organism against pathogens and maintain homeostasis (Gunzer et al., 2012). However, a well-functioning immune system can be

\footnotetext{
Corresponding authors

* Project supported by the Zhejiang Provincial Natural Science Foundation of China (No. LZ14C200001), the National Key Technology R \& D Program of China (No. 2012BAD33B08), and the Foundation of Fuli Institute of Food Science, Zhejiang University (2013), China (1D) ORCID: Wei CHEN, http://orcid.org/0000-0002-2373-2437

(C) Zhejiang University and Springer-Verlag Berlin Heidelberg 2016
}

disrupted by multiple factors, such as inadequate nutrition (Salva et al., 2012), physical, psychological, and environmental stresses (Srikumar et al., 2006; Li et al., 2012) as well as oxidative stress (Wang J.X. et al., 2012). Both in vitro and in vivo studies supported the possibility that oxidative stress may be the major underlying cause of inflammatory and immune dysfunction (Sordillo and Aitken, 2009). In the case of impaired immunity, the individual suffers from increased susceptibility to a variety of illnesses (Dietert and Zelikoff, 2010; Morris et al., 2013). As the same with some chronic diseases, prevention is much more effective than treatment in immune suppression, and naturally occurring bioactive compounds derived from foodstuff have made a great 
contribution as a result of few side-effects and lower toxicity (Gil and Rueda, 2002; Zhang et al., 2013).

American ginseng (Panax quinquefolius L.), mainly grown in the United States and Canada, has occupied a prominent position in the enhancement of immune function (Yuan et al., 2010; Lemmon et al., 2012). In the past few decades, information on certain phytochemical features as well as chemical composition of gensenosides of American ginseng has been obtained (Qi et al., 2011). Also, pharmacological effects of American ginseng have been discovered. Ginseng saponins or ginsenosides are generally considered to be the major active constituents responsible for several pharmacological effects on cardiovascular disease (Li et al., 2010), endocrine disorders (Mucalo et al., 2013), cognitive function (Yuan et al., 1998), immune system, and cancer (Ichikawa et al., 2009; Kim, 2012; Barton et al., 2013). Because of its health benefits, particularly for its immune-enhancing effects, American ginseng has been made into a variety of products (Lesser and Shick, 1989), like capsule, liquid, and tablet products. However, the bottled beverage product may be more innovative and prospective compared with those product types.

Jujube (Zizyphus jujuba Mill.), a native fruit from China with a history of over 4000 years, has been widely used for the production of food itself, food additives, and flavorings on account of its particular nutritional value (Wang, 2011; Gao et al., 2013). As a result of developments in food research, much work has been done on jujube in recent decades and the nature of the polysaccharides present in jujube has been studied (Li et al., 2007; Zhao et al., 2008). On account of the abundance of polysaccharides in jujube, much attention has been directed to their extensive bioactivities in regard to immunomodulation (Zhang et al., 2013), anti-cancer (Plastina et al., 2012), anti-virus (Yen et al., 2014), and anti-oxidation properties (Shen et al., 2009). Although, jujube fruits can be made into paste, puree, syrup, and preparations to aid digestion and general health, deep-processing jujube products are still rare. Hence, it is worth studying the deep-processing jujube product to fulfill its maximizing value.

Previous reports suggested that mixtures of some bioactive components may exert a better effect compared with compounds used individually (Huang et al., 2007), which has motivated us to develop a new formula called Shenzao Cha (SZC), comprising American ginseng and Chinese jujube. The product was formulated with stable levels of total saponins and polysaccharides. The objective of the present study is to evaluate the immunomodulatory effect of SZC in a normal mouse model and to determine its antioxidant activity which might be relevant to immune enhancement.

\section{Materials and methods}

\subsection{Materials}

The American ginseng extract (Batch No. 20130103) was purchased from Ningbo Liwah Pharmaceutical Co., Ltd. (Ningbo, China), and Chinese jujube (Batch No. 130627) was purchased from East China Medicine Slice Co., Ltd. (Hangzhou, China). Yeast artificial chromosome-1 (YAC-1) cell, a murine lymphoma cell line, was purchased from the Cell Bank of the Chinese Academy of Sciences (Shanghai, China). Fetal bovine serum was purchased from Zhejiang Tianhang Biological Technology Co., Ltd. (Hangzhou, China). Sheep red blood cells (SRBCs) were purchased from Sinri Bioengineering Co., Ltd. (Hangzhou, China). Nonidet P-40 (NP-40) was purchased from the Beyotime Institute of Biotechnology (Jiangsu, China). Trypan blue, 3-(4,5dimethyl-2-thiazolyl)-2,5-diphenyltetrazolium bromide (MTT), and concanavalin A (ConA) were purchased from Sigma (St. Louis, MO, USA). Roswell Park Memorial Institute 1640 (RPMI 1640) medium powder was purchased from Gibco (Grand Island, NY, USA). Ginsenoside Re, D-glucose, and isopropanol alcohol were purchased from Aladdin Industrial Co. (Shanghai, China). The 96-well round-bottom plates and 24-well plates were purchased from Corning Incorporated (New York, USA). Lactate dehydrogenase (LDH), superoxide dismutase (SOD), catalase (CAT), glutathione peroxidase (GSH-Px), and malondialdehyde (MDA) assay kits were purchased from the Nanjing Jiancheng Bioengineering Institute (Nanjing, China).

\subsection{Preparation of SZC}

The SZC utilized in this study was developed from American ginseng (P. quinquefolius L.) and Chinese jujube (Z. jujuba Mill.). The American 
ginseng extract was dissolved in sterile water at a concentration of $0.26 \%(2.6 \mathrm{~g} / \mathrm{L})$. Jujube extract was prepared as follows: pulp was soaked in water at a ratio of $1: 9(\mathrm{w} / \mathrm{w})$ for $1 \mathrm{~h}$, hydrolyzed with pectinase for $4 \mathrm{~h}$, then centrifuged at $3500 \mathrm{r} / \mathrm{min}$ for $15 \mathrm{~min}$. Jujube and American ginseng extract solution were mixed at a ratio of 2:5 (v/v) to generate SZC. Finally, SZC was concentrated with a rotary evaporator under reduced pressure, and the concentrated solution was diluted with sterile water before use.

The total saponin content was determined following the method described by Xie et al. (2012) and ginsenoside Re was used as the standard. The amount of total polysaccharide in the sample was measured by the phenol-sulfuric acid colorimetric method (Wang D. et al., 2012) with glucose as a standard. The total saponin and polysaccharide contents in SZC were 7.84 and $16.82 \mathrm{mg} / \mathrm{g}$ raw material, respectively.

\subsection{Animal experiments}

Specific pathogen-free (SPF) ICR male mice $((20 \pm 2) \mathrm{g})$ were purchased from Shanghai SuperB\&K Laboratory Animal Co., Ltd. (Shanghai, China) with a certificate No. SCXK (hu) 2013-0016. The mice were 6-7 weeks old at the start of the experiment. Mice were maintained in a temperature-controlled environment $\left((22 \pm 2){ }^{\circ} \mathrm{C}\right)$ with a $12 \mathrm{~h} / 12 \mathrm{~h}$ light/dark cycle and given free access to water and food throughout the experiment. Any aspect of the work that involved experimental animals and their care was approved by the Committee on the Ethics of Animal Experiments of Zhejiang University in compliance with the National Institutes of Health Guide for Care and Use of Laboratory Animals.

After an acclimation period of $5 \mathrm{~d}$, mice were randomly divided into four groups: control group (sterile water), $\mathrm{SZC}$ low-dose group (1.3 $\mathrm{g}$ raw material $/ \mathrm{kg}$ body weight (BW)), SZC medium-dose group (2.6 g raw material $/ \mathrm{kg} \mathrm{BW}$ ), and SZC high-dose group (5.2 g raw material $/ \mathrm{kg} \mathrm{BW}$ ). All animals received intragastric administration once daily for four weeks. The body weight of mice was weighed at the start, in the middle, and at the end of the experiment.

\subsection{Assay of spleen and thymus indices}

Twenty-four hours after the last intragastric administration, animals were weighed and sacrificed. Spleen and thymus were then excised and weighed immediately, and the organ indices were calculated according to the following formula: $W_{1} / W_{0}$, where $W_{1}$ is the weight of spleen or thymus, and $W_{0}$ is the weight of the whole body.

\subsection{Assay of serum hemolysis}

After 24-d administration, each mouse was immunized by intraperitoneal injection of $0.2 \mathrm{ml}$ suspension of $2 \%$ SRBCs. Four days later, blood from SRBC-immunized mice was collected and allowed to clot for $1-2 \mathrm{~h}$. Serum was collected by centrifugation at $2000 \mathrm{r} / \mathrm{min}$ for $10 \mathrm{~min}$. Assay of serum hemolysis was performed based on the method of Jiang et al. (2013). Briefly, the serum was diluted 500-fold with $0.9 \%(9 \mathrm{~g} / \mathrm{L}) \mathrm{NaCl}$, and $1 \mathrm{ml}$ of the diluted serum was mixed with $0.5 \mathrm{ml}$ of $10 \%$ SRBCs (in $0.9 \% \mathrm{NaCl}$ ) and $1 \mathrm{ml}$ of diluted guinea pig serum (1:10 (v/v) dilution). A blank control employing $0.9 \% \mathrm{NaCl}$ solution instead of mouse serum was prepared synchronously. After incubation at $37^{\circ} \mathrm{C}$ for $25 \mathrm{~min}$, the reaction was terminated in an ice bath. The samples were centrifuged at $2000 \mathrm{r} / \mathrm{min}$ for $10 \mathrm{~min}$ at $4{ }^{\circ} \mathrm{C}$, and supernatants were collected and mixed with 3 volumes of Drabkin's reagent $\left(1.0 \mathrm{~g} \mathrm{NaHCO}_{3}, 0.05 \mathrm{~g} \mathrm{KCN}, 0.2 \mathrm{~g}\right.$ $\mathrm{K}_{3} \mathrm{Fe}(\mathrm{CN})_{6}$, which was made up to $1 \mathrm{~L}$ with distilled water). At the same time, $0.25 \mathrm{ml}$ SRBCs were blended with $4 \mathrm{ml}$ Drabkin's reagent as half hemolysis. The absorbance at $540 \mathrm{~nm}$ was read against the blank control. The hemolytic activity was calculated according to the following formula: hemolytic complement activity $\left(\mathrm{HC}_{50}\right)=A_{\mathrm{s}} / A_{\mathrm{h}} \times 500$, where $A_{\mathrm{s}}$ is the absorbance of test sample, and $A_{\mathrm{h}}$ is the absorbance of half hemolysis.

\subsection{Assay of splenic lymphocyte proliferation}

Splenocyte proliferation was measured by an MTT assay as described by Yang et al. (2009) with some modifications. Mice spleens were collected aseptically, homogenized gently in Hank's solution with a pair of forceps, and passed through a 200-mesh fine steel sieve to obtain single-cell suspensions. After washing three times with Hank's solution, the splenocytes were re-suspended in RPMI 1640 complete medium (RPMI 1640 medium with 10\% fetal bovine serum, $100 \mathrm{U} / \mathrm{ml}$ streptomycin, and $100 \mathrm{U} / \mathrm{ml}$ penicillin) and adjusted to a concentration of $3 \times 10^{6}$ cells $/ \mathrm{ml}$. The cell numbers were counted by the trypan blue dye exclusion technique. Cell viability exceeded $95 \%$. 
Then, cell suspensions were seeded into 24-well plates at $1 \mathrm{ml} / \mathrm{well}$ and cultured with $7.5 \mu \mathrm{g} / \mathrm{ml}$ ConA as stimulated samples or without ConA as nonstimulated samples. The plates were placed in a humid atmosphere with $5 \% \mathrm{CO}_{2}$ at $37^{\circ} \mathrm{C}$. After $68 \mathrm{~h}$ of incubation, $50 \mu \mathrm{l}$ of MTT solution $(5 \mathrm{mg} / \mathrm{ml})$ was added to each well for another 4-h incubation. Finally, $1 \mathrm{ml}$ of isopropanol solution was added to fully solubilize the purple formazan crystals. The absorbance at $570 \mathrm{~nm}$ was read on an automated microplate reader.

The proliferation capacity of splenocytes was evaluated according to the following formula: $A_{\text {test }}{ }^{-}$ $A_{\text {control }}$, where $A_{\text {test }}$ is the absorbance of the stimulated sample, and $A_{\text {control }}$ is the absorbance of the nonstimulated sample.

\subsection{Assay of natural killer (NK) cell activity}

The splenic natural killer cell activity was determined by its cytotoxicity against YAC-1 using a LDH release assay. The assay was performed as previously described with some modifications (Lv et al., 2013). In brief, splenocytes, acting as effector cells, were prepared as described, and YAC-1 cells were used as target cells in their log phase. Effector cells and target cells were mixed in a ratio of 50:1 in the 96-well round-bottom plates and co-incubated at $37^{\circ} \mathrm{C}$ for $4 \mathrm{~h}$ in a humidified atmosphere of $5 \% \mathrm{CO}_{2}$. After incubation, supernatants were collected for the detection of LDH activity, following the instructions of the LDH cytotoxicity detection kit. The percentage of cell-mediated cytotoxicity was calculated according to the following formula: NK cell activity $(\%)=$ $\left(A_{\mathrm{f}}-A_{\mathrm{n}}\right) /\left(A_{\mathrm{m}}-A_{\mathrm{n}}\right) \times 100 \%$, where $A_{\mathrm{f}}$ is the $\mathrm{LDH}$ release due to the co-incubation of effector and target cells, $A_{\mathrm{n}}$ is the $\mathrm{LDH}$ release due to target cells incubated in the culture medium alone, and $A_{\mathrm{m}}$ is the $\mathrm{LDH}$ release achieved by the addition of $1 \%$ NP-40 to target cells.

\subsection{Biochemical assays}

Twenty-four hours after the last sample administration, the serum, liver, spleen, and thymus were collected and stored at $-80^{\circ} \mathrm{C}$ for biochemical assay. The tissues were minced and homogenized in 10 volumes of cold $0.9 \% \mathrm{NaCl}$. Homogenates were centrifuged at $3000 \mathrm{r} / \mathrm{min}$ at $4{ }^{\circ} \mathrm{C}$ for $10 \mathrm{~min}$. Protein contents in the homogenate supernatant were detected with the Coomassie brilliant blue method, while SOD,
GSH-Px, and CAT activities and MDA content were all determined with commercial available assay kits following the manufacturers' protocols.

SOD was determined according to the manufacturer's protocol of SOD assay kit A001-1. Briefly, to achieve the optimal detection range, $20 \mu \mathrm{l}$ of serum, $60 \mu \mathrm{l}$ of $0.5 \%$ ( $5 \mathrm{~g} / \mathrm{L})$ liver homogenate, $100 \mu \mathrm{l}$ of $2 \%$ $(0.02 \mathrm{~g} / \mathrm{ml})$ spleen homogenate, and $100 \mu \mathrm{l}$ of $2 \%$ $(0.02 \mathrm{~g} / \mathrm{ml})$ thymus homogenate were prepared and then used for determination of SOD, respectively. The absorbance was measured at $550 \mathrm{~nm}$ on a microplate reader.

CAT in this study was measured according to the manufacturer's protocol of CAT assay kit A007-1. Briefly, to achieve the optimal detection range, $20 \mu \mathrm{l}$ of serum, $60 \mu \mathrm{l}$ of $0.5 \%$ liver homogenate, $100 \mu \mathrm{l}$ of $2 \%$ spleen homogenate, and $100 \mu \mathrm{l}$ of $2 \%$ thymus homogenate were prepared for the determination of CAT, respectively. The absorbance of samples was detected at $405 \mathrm{~nm}$ at the end of reaction.

GSH-Px was determined based on the manufacturer's protocol of GSH-Px assay kit A005. Briefly, to achieve the optimal detection range, $100 \mu \mathrm{l}$ of 5-fold diluted serum, $200 \mu \mathrm{l}$ of $0.25 \%$ liver homogenate, $200 \mu \mathrm{l}$ of $1.5 \%$ spleen homogenate, and $200 \mu \mathrm{l}$ of $5 \%$ thymus homogenate were prepared and then used for determination of GSH-Px, respectively. The absorbance of samples was detected at $412 \mathrm{~nm}$ at the end of reaction.

MDA was determined according to the manufacturer's protocol of MDA assay kit A003-1. Briefly, to achieve the optimal detection range, $100 \mu \mathrm{l}$ of serum, $200 \mu \mathrm{l}$ of $10 \%$ liver homogenate, $200 \mu \mathrm{l}$ of $10 \%$ spleen homogenate, and $200 \mu \mathrm{l}$ of $10 \%$ thymus homogenate were prepared for the determination of MDA, respectively. The optical density (OD) of samples was measured at $450 \mathrm{~nm}$.

\subsection{Statistical analysis}

All statistical analyses were performed with SPSS software for Windows, Version 17.0 (SPSS Inc., Chicago, Illinois, USA). Quantitative data were evaluated by one-way analysis of variance (ANOVA) followed by the Duncan's test and expressed as the mean \pm standard error of the mean (SEM). $P$-values less than 0.05 were regarded as significant, while $P$-values less than 0.01 were considered to be extremely significant. 


\section{Results}

\subsection{Effects of SZC on body weight and spleen and thymus indices}

In order to investigate the immunomodulatory effect of SZC, we first studied its protection against degenerative changes of the spleen and thymus. Table 1 demonstrated that all doses of SZC significantly increased the spleen and thymus indices in mice $(P<0.01)$. In the high-dose group $(5.2 \mathrm{~g} / \mathrm{kg})$, the spleen and thymus indices were approximately 1.6and 1.9-fold higher than those in the control group, respectively.

Table 1 Effect of Shenzao Cha (SZC) on spleen and thymus indices

\begin{tabular}{lcc}
\hline \multicolumn{1}{c}{ Group } & $\begin{array}{c}\text { Spleen index } \\
(\mathrm{mg} / \mathrm{g})\end{array}$ & $\begin{array}{c}\text { Thymus index } \\
(\mathrm{mg} / \mathrm{g})\end{array}$ \\
\hline Control & $3.73 \pm 0.23$ & $1.12 \pm 0.10$ \\
$1.3 \mathrm{~g} / \mathrm{kg} \mathrm{SZC}$ & $5.74 \pm 0.19^{* *}$ & $1.83 \pm 0.09^{* *}$ \\
$2.6 \mathrm{~g} / \mathrm{kg} \mathrm{SZC}$ & $5.82 \pm 0.17^{* *}$ & $1.92 \pm 0.07^{* *}$ \\
$5.2 \mathrm{~g} / \mathrm{kg} \mathrm{SZC}$ & $5.96 \pm 0.22^{* *}$ & $2.11 \pm 0.12^{* *}$ \\
\hline${ }^{* *} P<0.01$ vs. control group. Data are expressed as mean $\pm \mathrm{SEM}$ \\
$(n=10)$
\end{tabular}

Mice in different groups showed similar body weights at the same time point (Fig. 1), and no death or abnormality was observed throughout the experiment. These results indicated that SZC could markedly increase spleen and thymus indices without side-effects on the body weight of healthy ICR mice.

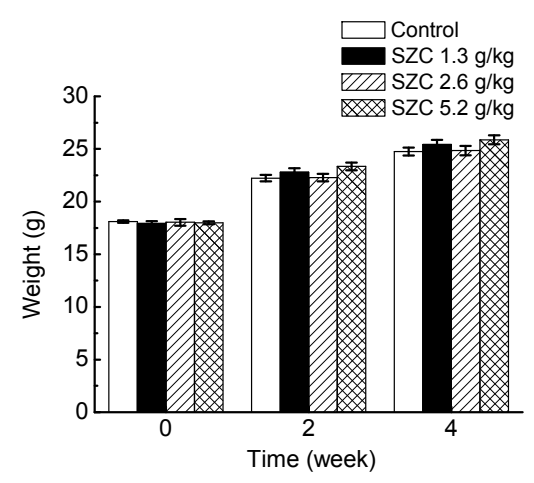

Fig. 1 Effect of Shenzao Cha (SZC) on the body weights of mice during the experiment period Data are expressed as mean \pm SEM $(n=10)$

\subsection{Effect of SZC on hemolytic activity}

Hemolytic complement activity $\left(\mathrm{HC}_{50}\right)$ was measured in SRBC-immunized mice to estimate the activity of serum hemolysis. As shown in Fig. 2a, $\mathrm{HC}_{50}$ values in the $\mathrm{SZC}$ administration groups were improved by $25.2 \%(1.3 \mathrm{~g} / \mathrm{kg}), 13.3 \%(2.6 \mathrm{~g} / \mathrm{kg})$, and $13.8 \%(5.2 \mathrm{~g} / \mathrm{kg})$, respectively, compared with the control group. A significant difference was found between the low-dose $(1.3 \mathrm{~g} / \mathrm{kg})$ group and control group $(P<0.05)$. Thus, our results suggested that oral administration of SZC could play a positive role in humoral immunity.
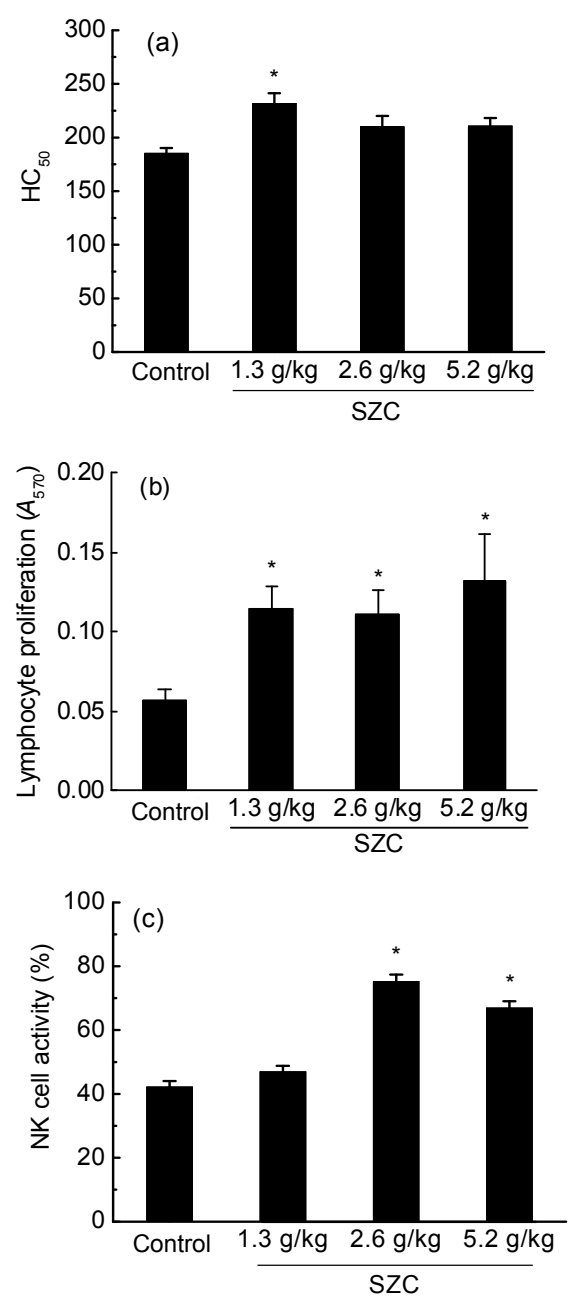

Fig. 2 Effect of Shenzao Cha (SZC) on the immune function in healthy ICR mice

(a) The formation of serum hemolysin; (b) The proliferation of splenic lymphocytes; (c) The activity of splenic NK cells. ${ }^{*} P<0.05$ vs. control group. Data are expressed as mean \pm SEM $(n=10)$ 


\subsection{Effect of SZC on splenic lymphocyte proliferation}

The effect of SZC on splenic lymphocyte proliferation was evaluated and the results are shown in Fig. 2b. In combination with T-cell mitogen (ConA, $7.5 \mu \mathrm{g} / \mathrm{ml})$, SZC $(1.3,2.6$, and $5.2 \mathrm{~g} / \mathrm{kg})$ administration markedly facilitated splenocyte proliferation. The largest lymphocyte proliferation, which was 1.4-fold higher than that in the control group, was observed in the high-dose $(5.2 \mathrm{~g} / \mathrm{kg})$ group. The positive effect of SZC on T-lymphocyte proliferation implies that it has the potential to enhance cellular immunity.

\subsection{Effect of SZC on splenic NK cell activity}

The amount of $\mathrm{LDH}$ released into culture medium from damaged YAC-1 cells was chosen as an indicator of NK cell activity and determined by colorimetric assay (Fig. 2c). The NK cell activities in 2.6 and $5.2 \mathrm{~g} / \mathrm{kg} \mathrm{SZC}$ administration groups were significantly enhanced compared with the control group. In particular, $2.6 \mathrm{~g} / \mathrm{kg} \mathrm{SZC}$ administration increased the NK cell activity by $78.6 \%$ relative to the control.

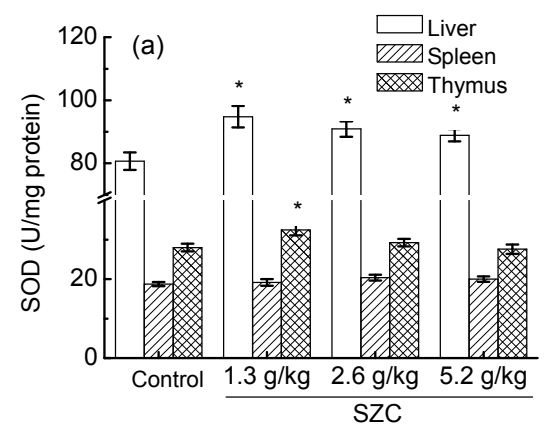

\subsection{Effects of SZC on the activities of SOD, GSH-Px, and CAT}

To examine the effect of SZC on antioxidant activity in mice, the activities of antioxidant enzymes (SOD, GSH-Px, and CAT) in liver, spleen, thymus, and serum were measured.

As illustrated in Figs. 3a and 3b, SOD activities in liver and serum were noticeably raised $(P<0.05)$ in all SZC-fed groups compared with controls. In thymus, the highest SOD activity was observed in the $1.3 \mathrm{~g} / \mathrm{kg}$ administration group. Medium- $(2.6 \mathrm{~g} / \mathrm{kg})$ and high-dose $(5.2 \mathrm{~g} / \mathrm{kg}) \mathrm{SZC}$ also showed a minimal promoting effect (Fig. 3a). No significant difference was noticed in spleen, although the amounts in SZC administration groups were higher than those in controls (Fig. 3a).

For GSH-Px activities in liver and thymus, low$(1.3 \mathrm{~g} / \mathrm{kg})$ and medium-dose $(2.6 \mathrm{~g} / \mathrm{kg}) \mathrm{SZC}$ both showed significant increases $(P<0.05$; Fig. $4 a)$. SZC administration $(1.3,2.6$, and $5.2 \mathrm{~g} / \mathrm{kg})$ all apparently raised the GSH-Px activity in serum compared with the sterile water control. In particular, $2.6 \mathrm{~g} / \mathrm{kg} \mathrm{SZC}$ administration increased the GSH-Px activity by

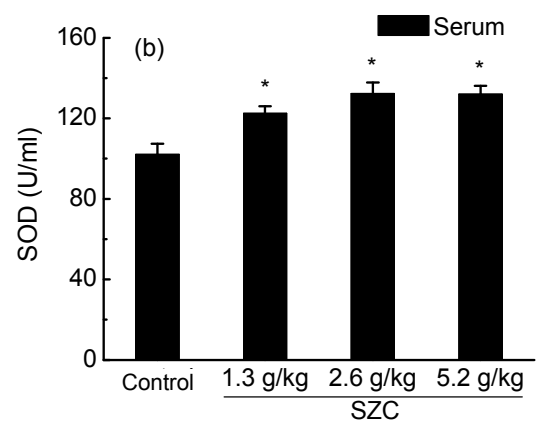

Fig. 3 Effects of Shenzao Cha (SZC) on the activities of SOD in liver, spleen, and thymus (a) and serum (b) ${ }^{*} P<0.05$ vs. control group. Data are expressed as mean \pm SEM $(n=8)$
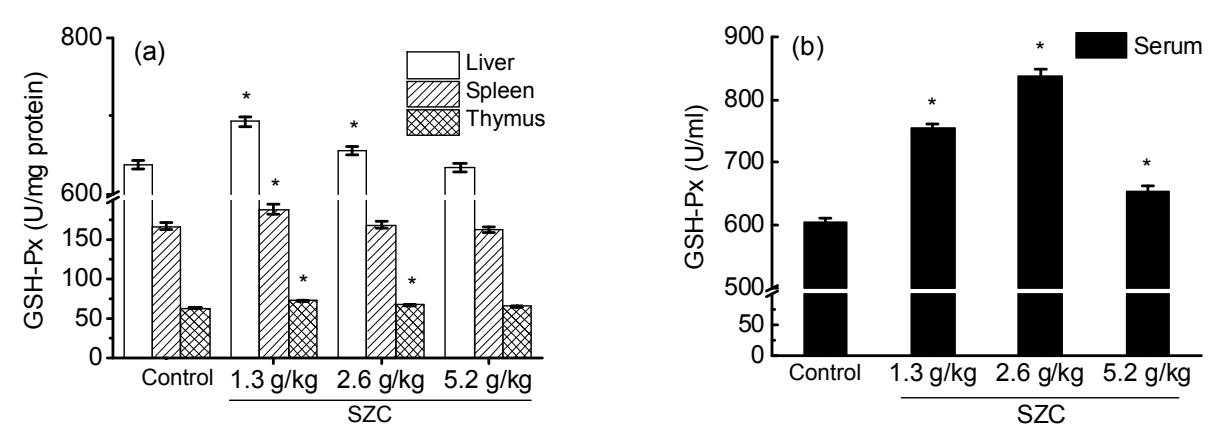

Fig. 4 Effects of Shenzao Cha (SZC) on the activities of GSH-Px in liver, spleen, and thymus (a) and serum (b) ${ }^{*} P<0.05$ vs. control group. Data are expressed as mean $\pm \operatorname{SEM}(n=8)$ 
$38.5 \%$ relative to controls (Fig. $4 \mathrm{~b}$ ). In the case of spleen, only low-dose $(1.3 \mathrm{~g} / \mathrm{kg})$ SZC significantly improved the GSH-Px activity (Fig. 4a).

As shown in Fig. 5a, the CAT activity in liver was significantly raised by SZC at all doses. Specifically, $1.3 \mathrm{~g} / \mathrm{kg}$ SZC administration exhibited the greatest increase. SZC administration also improved the CAT activity in spleen by $13.0 \%(1.3 \mathrm{~g} / \mathrm{kg})$, $37.8 \%(2.6 \mathrm{~g} / \mathrm{kg})$, and $55.0 \%(5.2 \mathrm{~g} / \mathrm{kg})$, respectively, relative to sterile water controls. Apart from the low-dose group, SZC administration groups displayed a significant difference compared with the control group (Fig. 5a). The greatest CAT activity in serum was observed in the $2.6 \mathrm{~g} / \mathrm{kg} \mathrm{SZC}$ treatment group. Low- $(1.3 \mathrm{~g} / \mathrm{kg})$ and high-dose $(5.2 \mathrm{~g} / \mathrm{kg})$ also showed a significant promoting effect (Fig. 5b).

\subsection{Effects of SZC on the content of MDA}

For liver, the contents of MDA in low- $(1.3 \mathrm{~g} / \mathrm{kg})$ and medium-dose $(2.6 \mathrm{~g} / \mathrm{kg})$ groups were significantly lower than those in controls (Fig. 6a). In serum, different doses of SZC significantly reduced the MDA levels by $25.5 \%(1.3 \mathrm{~g} / \mathrm{kg}), 40.8 \%(2.6 \mathrm{~g} / \mathrm{kg})$, and $24.1 \%(5.2 \mathrm{~g} / \mathrm{kg})$, respectively, relative to controls (Fig. 6b). SZC reduced the MDA contents in spleen and thymus to some extent, but only the difference between the low-dose group $(1.3 \mathrm{~g} / \mathrm{kg})$ and control was statistically significant (Fig. 6a).

\section{Discussion}

The immune system, consisting of innate and adaptive immunity, is the human's ultimate defense against infection. Moreover, it has been considered as a health indicator and longevity predictor. However, stress, fatigue, and chemotherapy can result in undesirable immune suppression (Srikumar et al., 2006; Wang J.X. et al., 2012). In addition, immune cell functions, such as microbicidal activity of phagocytes and the lymphoproliferative response to mitogens, are related to the generation of reactive oxygen species (ROS) (Goldstone and Hunt, 1997). Excessive accumulation of ROS can exert negative effects on immune cells. For example, they can attract cellular components by oxidizing membrane lipid and
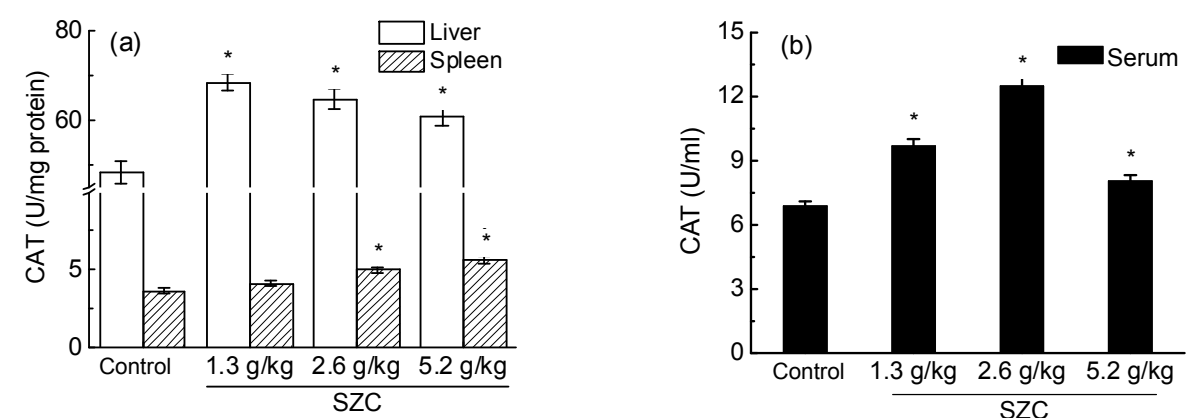

Fig. 5 Effects of Shenzao Cha (SZC) on the activities of CAT in liver and spleen (a) and serum (b)

${ }^{*} P<0.05$ vs. control group. Data are expressed as mean $\pm \operatorname{SEM}(n=8)$
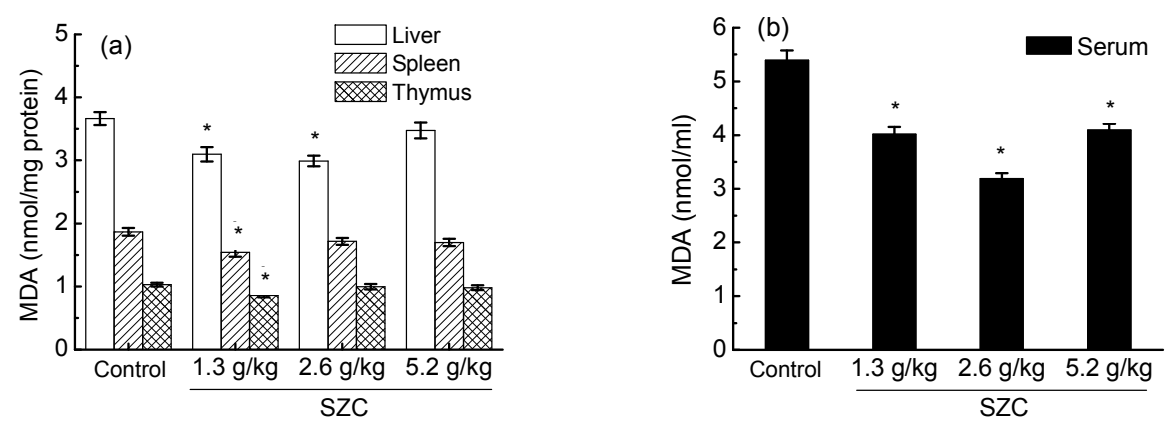

Fig. 6 Effects of Shenzao Cha (SZC) on the contents of MDA in liver, spleen, and thymus (a) and serum (b) ${ }^{*} P<0.05$ vs. control group. Data are expressed as mean $\pm \operatorname{SEM}(n=8)$ 
accelerating glutathione (GSH) depletion (D'Autreaux and Toledano, 2007) eventually resulting in oxidative damage and immune depression. It is noticeable that food materials which are rich in bioactive constituents can neutralize ROS, protect organisms from oxidative damage, and enhance immune function. Among those food materials, American ginseng and Chinese jujube have attracted great attention in recent decades for their diverse pharmacological activities, particularly in immunomodulatory activity. According to published reports, American ginseng extract can modulate the immune function by promoting antibody formation, cytokine production, and NK cell activity, and preventing the effects of oxidative stress in mice (Yuan et al., 2010). Polysaccharides extracted from jujube can increase thymus and spleen indices as well as enhance the proliferation of splenocytes and peritoneal macrophages in mice (Zhao et al., 2006; Gao et al., 2013). Therefore, we developed a formula (SZC) containing American ginseng and Chinese jujube extracts, and, for the first time, explored its immunomodulatory properties. Our results demonstrated that oral administration of SZC could significantly enhance immune function in ICR mice.

Adaptive immunity responses, including humoral and cellular immunity, are mainly dependent on B- and T-lymphocytes, respectively. Antibody response following immunization with a foreign antigen is the first to be studied, but still remains as an important assay of immune function (LeMaoult et al., 1997). When mice are immunized with SRBC, Blymphocytes would secrete hemolysin, whose content in serum is used to evaluate the functional status of humoral immunity (Yang et al., 2009). T-lymphocytes could eliminate the target cells directly as well as release various cytokines, and their proliferation is crucial for the activation cascade of both humoral and cellular immune responses (Chen et al., 2012). In the present study, serum hemolysin formation and T-lymphocyte proliferation with its mitogen ConA were determined to elucidate the effect of SZC on adaptive immunity. $\mathrm{HC}_{50}$ in $\mathrm{SZC}$ administration groups was significantly or numerically higher than that in controls (Fig. 2a), and T-lymphocyte proliferation was also markedly accelerated (Fig. 2b); this meant that both humoral and cellular immunities were improved. The response to $\mathrm{T}$-dependent antigen SRBC requires the co-operation of macrophages and T- and B-lymphocytes, which might explain why
SZC did not show an equivalent effect on $\mathrm{HC}_{50}$ and T-lymphocyte proliferation. As in several other studies (Zhu et al., 2007; Lv et al., 2013), the low-dose was found to be the most effective in serum hemolysin formation. As macrophages play an important role in the processing and presenting of antigen to $\mathrm{T}$ - and B-lymphocytes, suggesting that a dose increase might have induced down-regulation of the function of macrophages. In addition, SZC significantly increased the indices of spleen and thymus, in which lymphocytes reside and undergo differentiation and maturation. Based on these results, we proposed that SZC can markedly improve the adaptive immunity of ICR mice after a 4-week administration.

Besides the adaptive immunity, innate immunity is also critical to the host immune system. NK cells are large granular lymphocytes derived from bone marrow and reside primarily in the spleen (Durairaj et al., 2013). They are characterized by their ability to spontaneously kill pathogen-infected cells and tumor cells, thus acting as major components of innate immunity (Wu et al., 2007). The activity of NK cells is controlled by interaction between activating and inhibitory receptors expressed on NK cells and ligands presented on target cell surfaces (Tian et al., 2012). In the present study, the YAC-1 cell was utilized as the target cell and splenic NK cells were collected to assess the effect of SZC on NK cell activity. An apparent difference was observed between SZC-fed and control groups, which represented a more vigorous cytolytic activity of NK cells toward the target cells as well as a promotion of innate immunity by SZC administration. A similar phenomenon was also observed by See et al. (1997). Because NK cells not only recognize and kill tumor or virusinfected cells, but also regulate the activities of other immune cells via the secretion of cytokines and chemokines, such as interferon (IFN)- $\gamma$ and tumor necrosis factor (TNF)- $\alpha$ (Oshimi, 2007). Hence, further studies detecting these cytokines by ELISA are needed to understand more comprehensively the influence of SZC on NK cells.

Growing evidence implies oxidative stress as a mechanism contributing to the decline in physiological functions of the immune system (Sordillo and Aitken, 2009). Cells and organisms in the immune system are more susceptible to oxidative stress, as immune responses generally lead to the generation of ROS, especially in the "respiratory burst" stimulated 
by neutrophils and macrophages (Knight, 2000). Antioxidants play a pivotal role in scavenging the ROS, thereby protecting the tissues from oxidative damage and preserving adequate function. Likewise, the beneficial effects of antioxidants on immune functions in vitro and in vivo have been frequently observed. For example, Kim et al. (2012) reported that depletion of ascorbic acid could impair NK cell activity. Additionally, de la Fuente and Victor (2000) suggested that $N$-acetylcysteine and vitamin E could balance altered immune functions to optimum effect. In addition, results presented in this study indicated that the immunomodulatory effect of SZC might be due to antioxidant activities.

In order to avoid oxidative stress, diverse antioxidant defense mechanisms have been developed that can effectively scavenge ROS before causing oxidation to macromolecules (Sordillo and Aitken, 2009). Antioxidant enzymes are among the most efficient defense mechanisms, and the three primary enzymes involved in neutralizing ROS are SOD, CAT, and GSH-Px. MDA is one of the final decomposition products of lipid peroxidation (LPO), and reflects the extent of the injury suffered by cellular membranes (Fan et al., 2014). In the present study, SZC generated a significant increase of antioxidant enzyme activities in liver and serum (SOD, CAT, GSH-Px), as well as an evident decrease of MDA content. The oxidative stresses in spleen and thymus were also reduced to a certain extent. The results are similar to the previous studies in which antioxidant activities of American ginseng and Chinese jujube were observed (Kim et al., 2007; Shen et al., 2009; Wang J.X. et al., 2012). These findings suggested that the antioxidant activities of SZC might partially contribute to the immunomodulatory function.

\section{Conclusions}

In summary, SZC exhibited dramatic immunomodulatory effects in ICR mice through intragastric administration. Moreover, its antioxidant activities were also observed, which might contribute to the immune enhancement. Therefore, our findings provide experimental evidence that SZC can be used daily to improve one's health and immune function efficiently. We have not performed any metabolic studies on SZC, owing to complexity of metabolism in humans. Further studies are required to develop an effective administration of SZC, and to investigate the mechanism underlying the immunomodulation before administration in humans is performed.

\section{Compliance with ethics guidelines}

Zhuo-ping YU, Dong-dong XU, Lai-feng LU, Xiao-dong ZHENG, and Wei CHEN declare that they have no conflict of interest.

All institutional and national guidelines for the care and use of laboratory animals were followed.

\section{References}

Barton, D.L., Liu, H., Dakhil, S.R., et al., 2013. Wisconsin Ginseng (Panax quinquefolius) to improve cancer-related fatigue: a randomized, double-blind trial, $\mathrm{N} 07 \mathrm{C} 2 . J N C I$, 105(16): 1230-1238. http://dx.doi.org/10.1093/jnci/djt181

Chen, Y., Tang, J., Wang, X., et al., 2012. An immunostimulatory polysaccharide (SCP-IIa) from the fruit of Schisandra chinensis (Turcz.) Baill. Int. J. Biol. Macromol., 50(3): 844-848. http://dx.doi.org/10.1016/j.ijbiomac.2011.11.015

D'Autreaux, B., Toledano, M.B., 2007. ROS as signalling molecules: mechanisms that generate specificity in ROS homeostasis. Nat. Rev. Mol. Cell Biol., 8(10):813-824. http://dx.doi.org/10.1038/nrm2256

de la Fuente, M., Victor, V.M., 2000. Anti-oxidants as modulators of immune function. Immunol. Cell Biol., 78(1):49-54.

http://dx.doi.org/10.1046/j.1440-1711.2000.00884.x

Dietert, R.R., Zelikoff, J.T., 2010. Identifying patterns of immune-related disease: use in disease prevention and management. World J. Pediatr., 6(2):111-118. http://dx.doi.org/10.1007/s12519-010-0026-1

Durairaj, P., Breda, M., Miller, S.C., 2013. Quantitative augmentation of immune cells in elderly normal mice by short-term, daily consumption of an extract of North American ginseng (Panax quinquefolius). Biomed. Res., 24(2):199-205.

Fan, Y., Ma, L., Zhang, W., et al., 2014. The design of propolis flavone microemulsion and its effect on enhancing the immunity and antioxidant activity in mice. Int. J. Biol. Macromol., 65:200-207. http://dx.doi.org/10.1016/j.ijbiomac.2014.01.041

Gao, Q.H., Wu, C.S., Wang, M., et al., 2013. The Jujube (Ziziphus Jujuba Mill.) Fruit: a review of current knowledge of fruit composition and health benefits. $J$. Agric. Food Chem., 61(14):3351-3363. http://dx.doi.org/10.1021/jf4007032

Gil, A., Rueda, R., 2002. Interaction of early diet and the development of the immune system. Nutr. Res. Rev., 15(2):263-292 http://dx.doi.org/10.1079/NRR200248

Goldstone, S.D., Hunt, N.H., et al., 1997. Redox regulation of the mitogen-activated protein kinase pathway during 
lymphocyte activation. BBA-Mol. Cell. Res., 1355(3): 353-360.

http://dx.doi.org/10.1016/S0167-4889(96)00150-4

Gunzer, W., Konrad, M., Pail, E., et al., 2012. Exercise-induced immunodepression in endurance athletes and nutritional intervention with carbohydrate, protein and fat - what is possible, what is not? Nutrients, 4(9):1187-1212. http://dx.doi.org/10.3390/nu4091187

Huang, G.C., Wu, L.S., Chen, L.G., et al., 2007. Immunoenhancement effects of Huang Qi Liu Yi Tang in a murine model of cyclophosphamide-induced leucopenia. $J$. Ethnopharmacol., 109(2):229-235. http://dx.doi.org/10.1016/j.jep.2006.07.023

Ichikawa, T., Li, J., Nagarkatti, P., et al., 2009. American ginseng preferentially suppresses STAT/iNOS signaling in activated macrophages. J. Ethnopharmacol., 125(1): $145-150$.

http://dx.doi.org/10.1016/j.jep.2009.05.032

Jiang, C.X., Zhao, L., Li, S.L., et al., 2013. Preliminary characterization and immunostimulatory activity of polysaccharides from Glossaulax didyma. Food Chem. Toxicol., 62:226-230. http://dx.doi.org/10.1016/j.fct.2013.08.079

Kim, D.H., 2012. Chemical diversity of Panax ginseng, Panax quinquifolium, and Panax notoginseng. J. Ginseng Res., 36(1):1-15. http://dx.doi.org/10.5142/jgr.2012.36.1.1

Kim, J.E., Cho, H.S., Yang, H.S., et al., 2012. Depletion of ascorbic acid impairs NK cell activity against ovarian cancer in a mouse model. Immunobiology, 217(9):873-881. http://dx.doi.org/10.1016/j.imbio.2011.12.010

Kim, K.T., Yoo, K.M., Lee, J.W., et al., 2007. Protective effect of steamed American ginseng (Panax quinquefolius L.) on V79-4 cells induced by oxidative stress. $J$. Ethnopharmacol., 111(3):443-450. http://dx.doi.org/10.1016/j.jep.2007.01.004

Knight, J.A., 2000. Review: free radicals, antioxidants and the immune system. Ann. Clin. Lab. Sci., 30(2):145-158.

LeMaoult, J., Szabo, P., Weksler, M.E., 1997. Effect of age on humoral immunity, selection of the B-cell repertoire and B-cell development. Immunol. Rev., 160(1):115-126. http://dx.doi.org/10.1111/j.1600-065X.1997.tb01032.x

Lemmon, H.R., Sham, J., Chau, L.A., et al., 2012. High molecular weight polysaccharides are key immunomodulators in North American ginseng extracts: characterization of the ginseng genetic signature in primary human immune cells. J. Ethnopharmacol., 142(1):1-13. http://dx.doi.org/10.1016/j.jep.2012.04.004

Lesser, M.P., Shick, J.M., 1989. Effects of irraniance and ultraviolet-radiation on photodaptation in the zooxanthellae of Aiptasia pallida: primary production, photoinhibition, and enzymic defenses against oxygen-toxicity. Mar. Biol., 102(2):243-255. http://dx.doi.org/10.1007/BF00428286

Li, J.Q., Ichikawa, T., Jin, Y., et al., 2010. An essential role of Nrf2 in American ginseng-mediated anti-oxidative actions in cardiomyocytes. J. Ethnopharmacol., 130(2):222-230. http://dx.doi.org/10.1016/j.jep.2010.03.040

Li, J.W., Ding, S.D., Ding, X.L., 2007. Optimization of the ultrasonically assisted extraction of polysaccharides from Zizyphus jujuba cv. jinsixiaozao. J. Food Eng., 80(1): 176-183. http://dx.doi.org/10.1016/j.jfoodeng.2006.05.006

Li, W.J., Nie, S.P., Peng, X.P., et al., 2012. Ganoderma atrum polysaccharide improves age-related oxidative stress and immune impairment in mice. J. Agric. Food Chem., 60(6): 1413-1418. http://dx.doi.org/10.1021/jf204748a

Lv, Y.J., Huang, J.M., Cai, M., et al., 2013. A health food high-peptide meal alleviates immunosuppression induced by hydrocortisone and cyclophosphamide in mice. Food Funct., 4(9):1352-1359. http://dx.doi.org/10.1039/c3fo30230j

Morris, A.C., Anderson, N., Brittan, M., et al., 2013. Combined dysfunctions of immune cells predict nosocomial infection in critically ill patients. Br. J. Anaesth., 111(5):778-787. http://dx.doi.org/10.1093/bja/aet205

Mucalo, I., Jovanovski, E., Rahelic, D., et al., 2013. Effect of American ginseng (Panax quinquefolius L.) on arterial stiffness in subjects with type-2 diabetes and concomitant hypertension. J. Ethnopharmacol., 150(1):148-153. http://dx.doi.org/10.1016/j.jep.2013.08.015

Oshimi, K., 2007. Progress in understanding and managing natural killer-cell malignancies. Brit. J. Haematol., 139(4):532-544. http://dx.doi.org/10.1111/j.1365-2141.2007.06835.x

Plastina, P., Bonofiglio, D., Vizza, D., et al., 2012. Identification of bioactive constituents of Ziziphus jujube fruit extracts exerting antiproliferative and apoptotic effects in human breast cancer cells. J. Ethnopharmacol., 140(2):325-332. http://dx.doi.org/10.1016/j.jep.2012.01.022

Qi, L.W., Wang, C.Z., Yuan, C.S., 2011. Ginsenosides from American ginseng: chemical and pharmacological diversity. Phytochemistry, 72(8):689-699. http://dx.doi.org/10.1016/j.phytochem.2011.02.012

Salva, S., Cecilia Merino, M., Agueero, G., et al., 2012. Dietary supplementation with probiotics improves hematopoiesis in malnourished mice. PLOS ONE, 7(2):e31171. http://dx.doi.org/10.1371/journal.pone.0031171

See, D.M., Broumand, N., Sahl, L., et al., 1997. In vitro effects of echinacea and ginseng on natural killer and antibodydependent cell cytotoxicity in health subjects and chronic fatigue syndrome or acquired immunodeficiency syndrome patients. Immunopharmacology, 35(3):229-235. http://dx.doi.org/10.1016/S0162-3109(96)00125-7

Shen, X., Tang, Y., Yang, R., et al., 2009. The protective effect of Zizyphus jujube fruit on carbon tetrachloride-induced hepatic injury in mice by anti-oxidative activities. $J$. Ethnopharmacol., 122(3):555-560. http://dx.doi.org/10.1016/j.jep.2009.01.027

Sordillo, L.M., Aitken, S.L., 2009. Impact of oxidative stress on the health and immune function of dairy cattle. Vet. Immunol. Immunop., 128(1-3):104-109. 
http://dx.doi.org/10.1016/j.vetimm.2008.10.305

Srikumar, R., Parthasarathy, N.J., Manikandan, S., et al., 2006. Effect of Triphala on oxidative stress and on cellmediated immune response against noise stress in rats. Mol. Cell. Biochem., 283(1-2):67-74.

http://dx.doi.org/10.1007/s11010-006-2271-0

Tian, Z., Gershwin, M.E., Zhang, C., 2012. Regulatory NK cells in autoimmune disease. J. Autoimmun., 39(3):206-215. http://dx.doi.org/10.1016/j.jaut.2012.05.006

Wang, B., 2011. Chemical characterization and ameliorating effect of polysaccharide from Chinese jujube on intestine oxidative injury by ischemia and reperfusion. Int. J. Biol. Macromol., 48(3):386-391. http://dx.doi.org/10.1016/j.ijbiomac.2010.12.005

Wang, D., Zhao, Y., Jiao, Y., et al., 2012. Antioxidative and hepatoprotective effects of the polysaccharides from Zizyphus jujube cv. Shaanbeitanzao. Carbohyd. Polym., 88(4):1453-1459.

http://dx.doi.org/10.1016/j.carbpol.2012.02.046

Wang, J.X., Tong, X., Li, P.B., et al., 2012. Immunoenhancement effects of Shenqi Fuzheng injection on cyclophosphamide-induced immunosuppression in Balb/c mice. J. Ethnopharmacol., 139(3):788-795. http://dx.doi.org/10.1016/j.jep.2011.12.019

Wu, D., Pae, M., Ren, Z., et al., 2007. Dietary supplementation with white button mushroom enhances natural killer cell activity in C57BL/6 mice. J. Nutr., 137(6):1472-1477.

Xie, Z., Huang, H., Zhao, Y., et al., 2012. Chemical composition and anti-proliferative and anti-inflammatory effects of the leaf and whole-plant samples of diploid and tetraploid Gynostemma pentaphyllum (Thunb.) Makino. Food Chem., 132(1):125-133.

http://dx.doi.org/10.1016/j.foodchem.2011.10.043

Yang, H.Y., Liu, S.L., Ibrahim, S.A., et al., 2009. Oral administration of live Bifidobacterium substrains isolated from healthy centenarians enhanced immune function in BALB/c mice. Nutr. Res., 29(4):281-289. http://dx.doi.org/10.1016/j.nutres.2009.03.010

Yen, M.H., Lee, J.J., Yeh, C.F., et al., 2014. Yakammaoto inhibited human coxsackievirus B4 (CVB4)-induced airway and renal tubular injuries by preventing viral attachment, internalization, and replication. $J$. Ethnopharmacol., 151(3):1056-1063. http://dx.doi.org/10.1016/j.jep.2013.11.049

Yuan, C.S., Attele, A.S., Wu, J.A., et al., 1998. Modulation of American ginseng on brainstem GABAergic effects in rats. J. Ethnopharmacol., 62(3):215-222. http://dx.doi.org/10.1016/S0378-8741(98)00066-X

Yuan, C.S., Wang, C.Z., Wicks, S.M., et al., 2010. Chemical and pharmacological studies of saponins with a focus on American ginseng. J. Ginseng Res., 34(3):160-167. http://dx.doi.org/10.5142/jgr.2010.34.3.160

Zhang, J., Chen, J., Wang, D., et al., 2013. Immune-enhancing activity comparison of sulfated ophiopogonpolysaccharide and sulfated jujube polysaccharide. Int. J. Biol. Macromol., 52:212-217.

http://dx.doi.org/10.1016/j.ijbiomac.2012.09.025

Zhao, Z., Li, J., Wu, X., et al., 2006. Structures and immunological activities of two pectic polysaccharides from the fruits of Ziziphus jujuba Mill. cv. jinsixiaozao Hort. Food Res. Int., 39(8):917-923.

http://dx.doi.org/10.1016/j.foodres.2006.05.006

Zhao, Z., Liu, M., Tu, P., et al., 2008. Characterization of water soluble polysaccharides from organs of Chinese Jujube (Ziziphus jujuba Mill. cv. Dongzao). Eur. Food Res. Technol., 226(5):985-989. http://dx.doi.org/10.1007/s00217-007-0620-1

Zhu, X.L., Chen, A.F., Lin, Z.B., 2007. Ganoderma lucidum polysaccharides enhance the function of immunological effector cells in immunosuppressed mice. J. Ethnopharmacol., 111(2):219-226.

http://dx.doi.org/10.1016/j.jep.2006.11.013

\section{中文概要}

题 目: 复方西洋参和红柊制剂对小鼠免疫功能影响的 研究

目 的: 综合评价复方西洋参和红束制剂对于小鼠非特异 性免疫和特异性免疫的影响, 为开发新产品奠定 基础。

创新点: 本文首次以西洋参提取物和红冭提取物为原料制 成复方制剂, 并通过动物实验发现该制剂具有增 强免疫功能, 为开发功能性食品提供新思路。

方 法: 将西洋参与红患提取物按一定比例制备复方制 剂, 以 $1.3 、 2.6$ 和 $5.2 \mathrm{~g} / \mathrm{kg}$ 为低、中和高剂量给 健康 ICR 小鼠连续灌胃此复方制剂 4 周, 对照组 灌胃同等剂量的无菌水, 最后通过测定免疫相关 指标对该复方制剂的免疫调节功能进行综合评 价。

结 论: 此款复方制剂可以显著提高小鼠的胸腺和脾脏指 数 (表 1), 同时低剂量组小鼠的血清溶血素水 平显著高于对照组, 高剂量组小鼠的脾淋巴细胞 增值能力约是对照组的 2.4 倍, 自然杀伤细胞的 活性也得到显著增强, 中剂量组小鼠的 NK 细胞 活性与对照组相比提高了 $78.6 \%$ （图 2)。另外, 此复方制剂能有效提高小鼠组织 (肝脏、脾脏和 胸腺) 和血清中超氧化物歧化酶 (SOD) 、谷胱 甘肽过氧化物酶 (GSH-Px)、过氧化氢酶 (CAT) 的活性, 同时降低丙二醛 (MDA) 的含量 (图 3 6)。综上所述, 此复方西洋参和红柊制 剂可有效提高健康 ICR 小鼠的非特异性和特异 性免疫功能, 而其抗氧化功能有可能是其免疫调 节活性的作用机制之一。

关键词: 西洋参; 红柊; 免疫调节; 抗氧化活性 